Article

\title{
Thermal Optimization of Horizontal Tubes with Tilted Rectangular Fins under Free Convection for the Cooling of Electronic Devices
}

\author{
Jong Bum Lee, Hyun Jung Kim and Dong-Kwon Kim * \\ Department of Mechanical Engineering, Ajou University, Suwon 16499, South Korea; eamice@ajou.ac.kr (J.B.L.); \\ hyunkim@ajou.ac.kr (H.J.K.) \\ * Correspondence: dkim@ajou.ac.kr; Tel.: +82-31-219-3660
}

Academic Editor: Xianchang Li

Received: 24 February 2017; Accepted: 28 March 2017; Published: 2 April 2017

\begin{abstract}
In the present work, the horizontal tubes with tilted rectangular fins under free convection are experimentally investigated for the cooling of electronic devices. The temperature differences of horizontal tubes with tilted rectangular fins are measured for several heat inputs, tilt angles, and numbers of fins. Using the measurement results, a correlation for the prediction of the Nusselt number is suggested. This correlation is suitable for the situation for Rayleigh numbers of 200,000-1,100,000, tilt angles of $0^{\circ}-90^{\circ}$, and numbers of fins of 9-36. On the basis of the correlation, the cooling performances are presented for various numbers of fins and thicknesses of fins, and the value of the optimal cooling performance is found. Finally, the optimal cooling performances of tubes with tilted rectangular fins and conventional radial rectangular fins are compared. The comparison results show that the optimal cooling performance of the tube with tilted fins is $6 \%$ greater than that of the tube with radial rectangular fins.
\end{abstract}

Keywords: free convection; tilted rectangular fin; horizontal finned tube

\section{Introduction}

Continuous miniaturization and performance enhancement of electronic devices have resulted in a rapid increase in the amount of heat generated in electronic devices [1-4]. Without proper thermal management, high rates of heat generation cause excessively high junction temperatures, which degrade the performance and reliability of devices. For example, in the case of light-emitting diodes (LEDs), the light output decreases as the temperature rises, because the quantum efficiency decreases at higher temperatures due to an increase in non-radiative recombinations through defect states [5-8]. The long-term stability and lifetime of LEDs also decrease with the increasing junction temperature $[9,10]$. Therefore, thermal management is essential for the maintenance of the performance and the durability of electronic devices [11,12]. Among several cooling techniques suggested for thermal management, natural convective heat sinks are the most widely used because of their high reliability, low cost, zero acoustic noise, and zero power consumption $[5,13]$.

There has been a great deal of research work on the heat sinks under free convection $[14,15]$. In particular, finned horizontal tubes under free convection have been investigated by many previous researchers. This is mainly because finned horizontal tubes are very widely used in various heat exchangers [16]. In the case of the gas-to-liquid heat exchanger, thermal resistance of the gas side is much greater than that of the liquid side, if there are no fins on the gas side [16]. As a result, finned horizontal tubes are commonly used to reduce thermal resistance of the gas side to improve overall thermal performance of the heat exchanger. Heat exchangers with finned horizontal tubes are widely used in many engineering applications, including refrigerators, air conditioners, and heat pumps. 
Square vertical fins mounted on horizontal tubes under free convection were studied by Chen and Chou, and Sparrow and Bahrami $[17,18]$. Annular fins of horizontal finned tube were investigated experimentally, and Nusselt number correlations were developed by Hahne and Zhu, and Yildiz and Yüncü $[19,20]$. Rectangular fins of radial heat sinks under free convection were investigated experimentally and numerically by Yu et al. [21,22]. Tubes with radial rectangular fins, as shown in Figure 1, are some of the most widely used heat sinks for the cooling of LED lighting. These finned tubes were investigated experimentally and Nusselt number correlations were developed by the present authors [23,24].

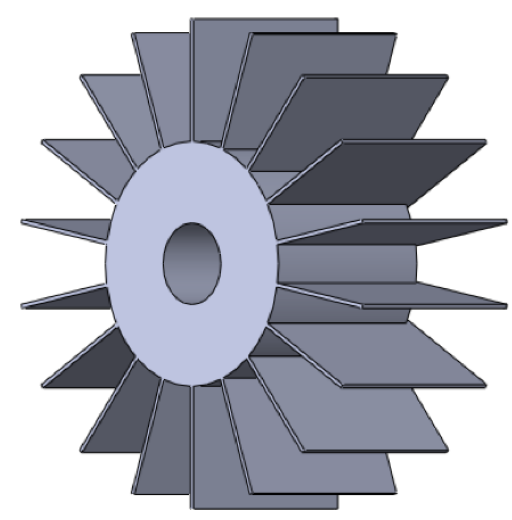

Figure 1. Tube with radial rectangular fins.

Considerable efforts have been aimed at investigating heat transfer through tilted fins. For example, the thermal performances of tilted pin fins in rectangular ducts were investigated by Takeishi et al. [25]. They concluded that tilted pin fins dissipate heat more effectively compared to normal pin fins because of the greater surface area of the tilted pin fins. Experimental and numerical investigation on tilted rectangular fins mounted on vertical plates under free convection was conducted by Hagote and Dahake [26]. They showed that tilted rectangular fins have higher thermal performances compared to normal rectangular fins when the tilt angle is $60^{\circ}$. Recently, the present authors conducted an investigation to compare the thermal performances of tilted rectangular fins mounted on vertical tubes under free convection to those of conventional radial rectangular fins [27]. It was shown that the cooling performance of a vertical tube with rectangular fins can be enhanced by as much as $30 \%$ by tilting the rectangular fins. Therefore, it is expected that the cooling performance of radial rectangular fins mounted on horizontal tubes, shown in Figure 1, under free convection can be enhanced by tilting fins, as shown in Figure 2. However, to the best of our knowledge, tilted rectangular fins mounted on horizontal tubes under free convection have not been investigated experimentally yet. As a result, in the case of horizontal configuration, the degree of cooling enhancement of rectangular fins on horizontal tubes by tilting fins and the conditions under which this enhancement is maximized are not clear, because free convection is strongly orientation-dependent.

Therefore, in the present study, the horizontal tubes with tilted rectangular fins under free convection are investigated experimentally for the cooling of electronic devices, as an extension of our previous work on the vertical tubes [27]. The temperature differences of horizontal tubes with tilted rectangular fins are measured for several heat inputs, tilt angles, and numbers of fins. Using the measurement results, a correlation for the prediction of the Nusselt number is suggested. On the basis of the correlation, the cooling performances are presented for various numbers of fins and thicknesses of fins, and the value of the optimal cooling performance is found. Finally, the optimal cooling performances of tubes with tilted rectangular fins and conventional radial rectangular fins are compared. 


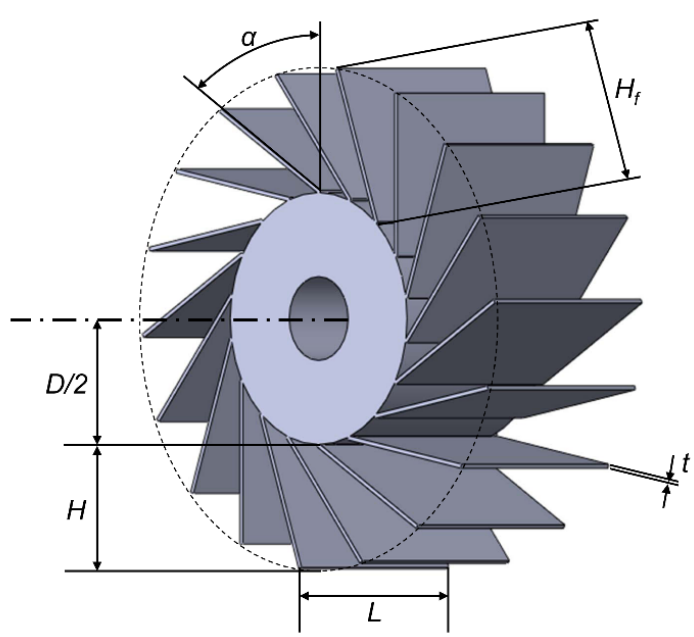

(a)

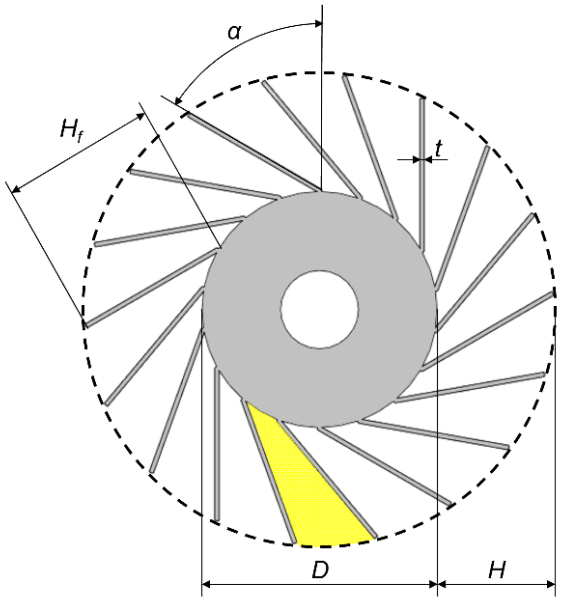

(b)

Figure 2. Tube with tilted rectangular fins. (a) Schematic drawing; (b) Top view ( $\alpha$ : tilt angle, $H_{f}$ : fin height, $t$ : fin thickness, $D$ : tube diameter, $H$ : heat sink height).

\section{Experimental Investigation}

The temperature differences of tubes with tilted rectangular fins under free convection were measured with respect to several heat inputs, tilt angles, and numbers of fins. Schematic drawings of the tube with tilted fins are shown in Figure 2, and the dimensions are listed in Table 1. Eleven different tilted finned tubes with various numbers of fins and tilt angles were tested. However, the case with large tilt angle $\left(\alpha=90^{\circ}\right)$ and large number of fins $(N=36)$ was excluded in the test, because the fin spacing was excessively small, and adjacent fins touch and bend each other. An aluminum alloy tube and a cylindrical heater were assembled first (Figure 3a). The cylindrical heater used in the present study was a cartridge heater. The electrical resistance of the heater was $15 \Omega$ and the maximum heating capacity was $60 \mathrm{~W}$. For the proper assembly, a thermal interface material was applied between the tube and the heater to enhance the contact between the tube and the heater. The thermal interface material used in the present study was a TC-5080 thermally conductive compound from Dow Corning. The thermal conductivity of this compound is $1 \mathrm{~W} / \mathrm{m} \cdot \mathrm{K}$ and the resulting contact resistance was $0.0022 \mathrm{~K} / \mathrm{W}$. Then, aluminum alloy fins were attached on the tube via interference fitting. The Teflon cylinders were used to support the tube and to insulate the left and right sides of the tube (Figure $3 b, c)$. The heater in the tube was powered by a DC power supply (E3633A; Agilent Technology, Santa Clara, CA, USA). Power of 2-38 W was applied to the heater. Four T-type thermocouples were circumferentially attached to the outer surface of tube to measure the tube 
temperatures. For temperature data acquisition from thermocouples, an acquisition unit (34970A DAQ; Agilent Technology, Santa Clara, CA, USA) was used. The temperatures were recorded when the fluctuations of the temperatures were smaller than $\pm 0.1^{\circ} \mathrm{C}$ for two minutes. The experiments were conducted in a quiescent and isolated place. The uncertainty analysis was conducted after finishing the experiments (Appendix A).

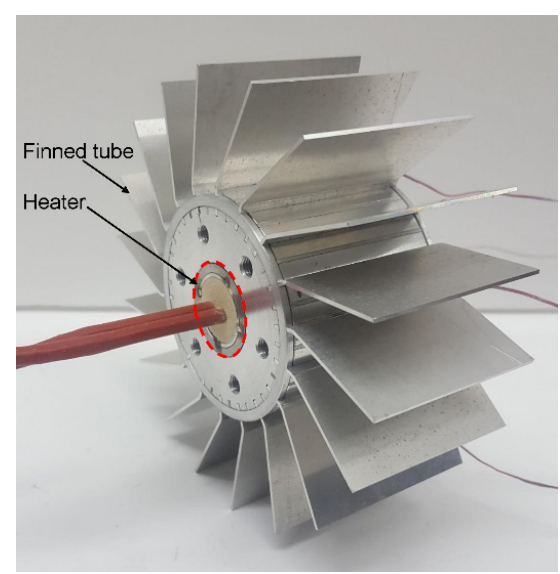

(a)

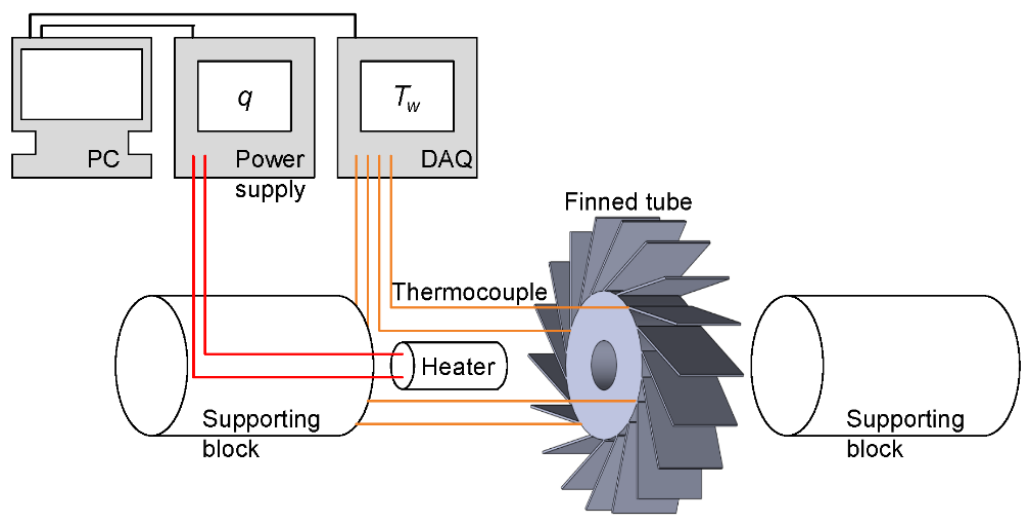

(b)

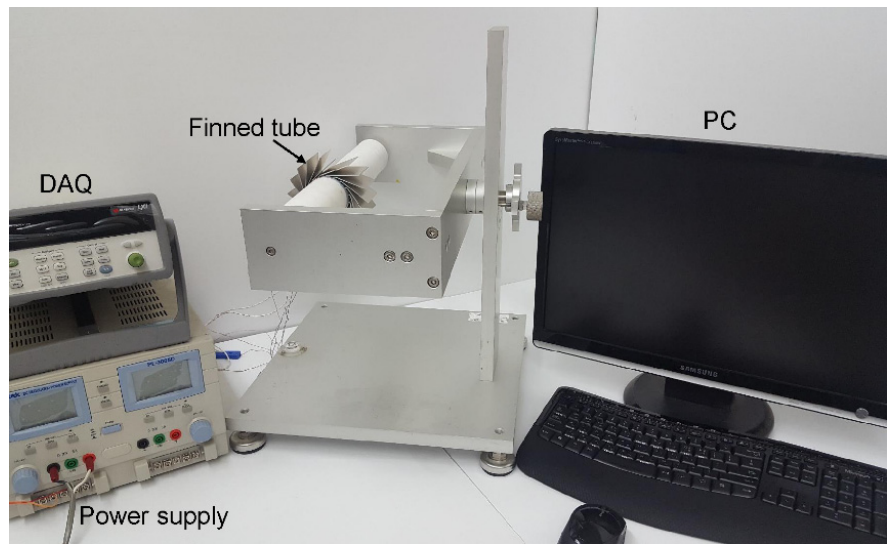

(c)

Figure 3. Test setup. (a) Image of a tube with tilted rectangular fins; (b) Schematic diagram of the test setup; (c) Image of the test setup (DAQ: Data acquisition unit, PC: Personal computer). 
Table 1. Dimensions of tested tubes with tilted fins.

\begin{tabular}{|c|c|c|c|c|c|c|}
\hline No. & $N$ & $\alpha$ & $L$ & $D$ & $H$ & $t$ \\
\hline 1 & 9 & \multirow{3}{*}{$90^{\circ}$} & \multirow{11}{*}{$50 \mathrm{~mm}$} & \multirow{11}{*}{$60 \mathrm{~mm}$} & \multirow{11}{*}{$30 \mathrm{~mm}$} & \multirow{11}{*}{$1.0 \mathrm{~mm}$} \\
\hline 2 & 12 & & & & & \\
\hline 3 & 18 & & & & & \\
\hline 4 & 9 & \multirow{4}{*}{$60^{\circ}$} & & & & \\
\hline 5 & 12 & & & & & \\
\hline 6 & 18 & & & & & \\
\hline 7 & 36 & & & & & \\
\hline 8 & 9 & \multirow{4}{*}{$30^{\circ}$} & & & & \\
\hline 9 & 12 & & & & & \\
\hline 10 & 18 & & & & & \\
\hline 11 & 36 & & & & & \\
\hline
\end{tabular}

\section{Results and Discussion}

The measurement results on the temperature differences between the tube and the surroundings $\left(T_{t}-T_{s}\right)$ for several tilt angles $(\alpha)$, numbers of fins $(N)$, and heat inputs $(q)$ are shown in Table 2 and Figure 4. From the measurement results, the cooling performances of tilted finned tubes are calculated and presented in Table 2 and Figure 5. In the present study, the thermal conductance, which is a reciprocal of the thermal resistance $R_{t h}$, is used as an index of cooling performance. The thermal conductance $1 / R_{t h}$ can be defined as:

$$
\frac{1}{R_{t h}} \equiv \frac{q}{T_{t}-T_{s}}
$$

The thermal conductance $1 / R_{t h}$ is the heat dissipation rate per unit temperature difference between the tube and the surroundings. As shown in Figure 5, the cooling performance of the horizontal tube with tilted rectangular fins is maximized when $\alpha=60^{\circ}$ and $N=36$. According to Figure 4 in [27], in the case of vertical configuration, the cooling performance is also maximized when $\alpha=60^{\circ}$ and $N=36$. Therefore, among eleven tested finned tubes, the tilted finned tube with $\alpha=60^{\circ}$ and $N=36$ is the best, regardless of configuration.

The thermal conductance $1 / R_{t h}$ can be expressed as a function of the effective surface area $A_{\text {eff, }}$ the unfinned surface area $A_{b}$, the fin surface area $A_{f}$, the heat transfer coefficient $h$, and the fin efficiency $\eta$ :

$$
\frac{1}{R_{t h}}=h A_{e f f}=h\left(A_{b}+\eta N A_{f}\right)
$$

where

$$
\begin{gathered}
A_{b}=\pi D L-N L t \\
A_{f}=L t+2 H_{f} t+2 H_{f} L \\
h=N u_{D} k_{f} / D \\
\eta=\frac{\sqrt{h p k_{s} A_{c}}}{h A_{f}} \frac{\left(h / \sqrt{\frac{h p}{k_{s} A_{c}}} k_{s}\right)+\tanh \left(\sqrt{\frac{h p}{k_{s} A_{c}}} H_{f}\right)}{\left(h / \sqrt{\frac{h p}{k_{s} A_{c}}} k_{s}\right) \tanh \left(\sqrt{\frac{h p}{k_{s} A_{c}}} H_{f}\right)+1}
\end{gathered}
$$

Here, $k_{f}$ and $k_{s}$ are the thermal conductivities of the fluid and the solid, respectively. In Equation (6), the convection heat transfer from the fin tip is considered. The fin height $H_{f}$, the fin perimeter $p$, and the fin cross-sectional area $A_{c}$ are given as:

$$
\begin{gathered}
H_{f}=\sqrt{H D+H^{2}+D^{2} \cos ^{2} \alpha / 4}-D \cos \alpha / 2 \\
p=2 t+2 L \\
A_{c}=L t
\end{gathered}
$$


Table 2. Cooling performances and Nusselt numbers calculated from measurement results.

\begin{tabular}{|c|c|c|c|c|c|c|}
\hline No. & $\alpha$ & $N$ & $T_{t}-T_{s}\left[{ }^{\circ} \mathrm{C}\right]$ & $q[\mathrm{~W}]$ & $1 / R_{t h}\left[\mathrm{~W} /{ }^{\circ} \mathrm{C}\right]$ & $N u_{D}$ \\
\hline \multirow{5}{*}{1} & \multirow{5}{*}{$90^{\circ}$} & \multirow{5}{*}{9} & $10.4 \pm 0.5$ & $2.24 \pm 0.01$ & $0.216 \pm 0.011$ & $8.71 \pm 0.44$ \\
\hline & & & $20 \pm 0.5$ & $4.58 \pm 0.02$ & $0.228 \pm 0.006$ & $9.23 \pm 0.25$ \\
\hline & & & $30.6 \pm 0.5$ & $7.57 \pm 0.01$ & $0.247 \pm 0.004$ & $9.99 \pm 0.17$ \\
\hline & & & $40.4 \pm 0.6$ & $10.61 \pm 0.02$ & $0.263 \pm 0.004$ & $10.61 \pm 0.15$ \\
\hline & & & $49.9 \pm 0.6$ & $14.39 \pm 0.02$ & $0.289 \pm 0.003$ & $11.66 \pm 0.14$ \\
\hline \multirow{5}{*}{2} & \multirow{5}{*}{$90^{\circ}$} & \multirow{5}{*}{12} & $10.1 \pm 0.5$ & $2.27 \pm 0$ & $0.226 \pm 0.011$ & $7.14 \pm 0.36$ \\
\hline & & & $20.5 \pm 0.5$ & $5.53 \pm 0.01$ & $0.269 \pm 0.007$ & $8.51 \pm 0.22$ \\
\hline & & & $30.3 \pm 0.6$ & $8.99 \pm 0.02$ & $0.297 \pm 0.006$ & $9.39 \pm 0.18$ \\
\hline & & & $39.7 \pm 0.5$ & $12.83 \pm 0.02$ & $0.323 \pm 0.004$ & $10.22 \pm 0.14$ \\
\hline & & & $50.3 \pm 0.6$ & $16.91 \pm 0.02$ & $0.336 \pm 0.004$ & $10.63 \pm 0.12$ \\
\hline \multirow{5}{*}{3} & \multirow{5}{*}{$90^{\circ}$} & \multirow{5}{*}{18} & $10.8 \pm 0.5$ & $2.79 \pm 0.01$ & $0.26 \pm 0.012$ & $5.71 \pm 0.27$ \\
\hline & & & $21.1 \pm 0.7$ & $6.53 \pm 0.04$ & $0.309 \pm 0.01$ & $6.81 \pm 0.22$ \\
\hline & & & $29.5 \pm 0.8$ & $10.37 \pm 0.05$ & $0.352 \pm 0.01$ & $7.75 \pm 0.21$ \\
\hline & & & $40.4 \pm 0.5$ & $15.28 \pm 0.01$ & $0.378 \pm 0.005$ & $8.32 \pm 0.11$ \\
\hline & & & $49.9 \pm 0.6$ & $20.28 \pm 0.03$ & $0.406 \pm 0.005$ & $8.94 \pm 0.12$ \\
\hline \multirow{5}{*}{4} & \multirow{5}{*}{$60^{\circ}$} & \multirow{5}{*}{9} & $10.3 \pm 0.5$ & $2.29 \pm 0.02$ & $0.221 \pm 0.011$ & $11.28 \pm 0.59$ \\
\hline & & & $20.6 \pm 0.6$ & $4.92 \pm 0.03$ & $0.239 \pm 0.007$ & $12.16 \pm 0.36$ \\
\hline & & & $29.9 \pm 0.5$ & $7.63 \pm 0.02$ & $0.255 \pm 0.005$ & $13.01 \pm 0.24$ \\
\hline & & & $40 \pm 0.6$ & $10.31 \pm 0.03$ & $0.258 \pm 0.004$ & $13.14 \pm 0.21$ \\
\hline & & & $49 \pm 0.5$ & $13.42 \pm 0.02$ & $0.274 \pm 0.003$ & $13.95 \pm 0.15$ \\
\hline \multirow{5}{*}{5} & \multirow{5}{*}{$60^{\circ}$} & \multirow{5}{*}{12} & $10.7 \pm 0.5$ & $2.42 \pm 0$ & $0.226 \pm 0.011$ & $9.11 \pm 0.43$ \\
\hline & & & $20.5 \pm 0.8$ & $5.47 \pm 0.05$ & $0.267 \pm 0.011$ & $10.74 \pm 0.44$ \\
\hline & & & $29.7 \pm 1.3$ & $9.11 \pm 0.1$ & $0.306 \pm 0.014$ & $12.35 \pm 0.56$ \\
\hline & & & $39.9 \pm 0.6$ & $12.19 \pm 0.03$ & $0.305 \pm 0.005$ & $12.3 \pm 0.2$ \\
\hline & & & $50.6 \pm 0.5$ & $16.61 \pm 0.02$ & $0.328 \pm 0.004$ & $13.21 \pm 0.14$ \\
\hline \multirow{5}{*}{6} & \multirow{5}{*}{$60^{\circ}$} & \multirow{5}{*}{18} & $10 \pm 0.7$ & $2.98 \pm 0.04$ & $0.297 \pm 0.02$ & $8.44 \pm 0.56$ \\
\hline & & & $20.3 \pm 0.7$ & $6.86 \pm 0.04$ & $0.338 \pm 0.012$ & $9.6 \pm 0.33$ \\
\hline & & & $30.9 \pm 0.7$ & $11.66 \pm 0.04$ & $0.377 \pm 0.009$ & $10.73 \pm 0.24$ \\
\hline & & & $39.4 \pm 0.7$ & $16.54 \pm 0.05$ & $0.419 \pm 0.008$ & $11.92 \pm 0.23$ \\
\hline & & & $51.2 \pm 1$ & $21.85 \pm 0.07$ & $0.427 \pm 0.008$ & $12.13 \pm 0.23$ \\
\hline & & & $10 \pm 0.6$ & $3.16 \pm 0.02$ & $0.315 \pm 0.018$ & $4.76 \pm 0.28$ \\
\hline & & & $19.9 \pm 0.5$ & $7.62 \pm 0.01$ & $0.383 \pm 0.01$ & $5.78 \pm 0.15$ \\
\hline 7 & $60^{\circ}$ & 36 & $29.6 \pm 0.7$ & $13.32 \pm 0.04$ & $0.451 \pm 0.01$ & $6.8 \pm 0.16$ \\
\hline & & & $39.7 \pm 0.7$ & $19.93 \pm 0.05$ & $0.502 \pm 0.009$ & $7.57 \pm 0.14$ \\
\hline & & & $51.7 \pm 1.1$ & $28.51 \pm 0.08$ & $0.551 \pm 0.011$ & $8.31 \pm 0.17$ \\
\hline & & & $10.2 \pm 1$ & $1.99 \pm 0.07$ & $0.195 \pm 0.02$ & $11.55 \pm 1.17$ \\
\hline & & & $20.2 \pm 0.8$ & $3.89 \pm 0.03$ & $0.192 \pm 0.007$ & $11.4 \pm 0.44$ \\
\hline 8 & $30^{\circ}$ & 9 & $29.7 \pm 0.7$ & $6.31 \pm 0.13$ & $0.212 \pm 0.007$ & $12.59 \pm 0.39$ \\
\hline & & & $40.1 \pm 0.9$ & $9.12 \pm 0.2$ & $0.227 \pm 0.007$ & $13.49 \pm 0.42$ \\
\hline & & & $51.5 \pm 1.6$ & $12.72 \pm 0.55$ & $0.247 \pm 0.013$ & $14.65 \pm 0.77$ \\
\hline & & & $10 \pm 0.9$ & $2.19 \pm 0.06$ & $0.219 \pm 0.021$ & $10.36 \pm 0.99$ \\
\hline & & & $19.2 \pm 1.6$ & $4.48 \pm 0.13$ & $0.233 \pm 0.021$ & $11.02 \pm 0.97$ \\
\hline 9 & $30^{\circ}$ & 12 & $30.6 \pm 1.4$ & $7.64 \pm 0.11$ & $0.249 \pm 0.012$ & $11.81 \pm 0.56$ \\
\hline & & & $41.4 \pm 1.4$ & $11.37 \pm 0.11$ & $0.274 \pm 0.009$ & $12.99 \pm 0.45$ \\
\hline & & & $48.8 \pm 1.5$ & $14.3 \pm 0.12$ & $0.293 \pm 0.009$ & $13.88 \pm 0.44$ \\
\hline & & & $10.1 \pm 0.5$ & $2.51 \pm 0.01$ & $0.248 \pm 0.012$ & $8.35 \pm 0.42$ \\
\hline & & & $20.1 \pm 0.5$ & $5.99 \pm 0.01$ & $0.298 \pm 0.008$ & $10.05 \pm 0.26$ \\
\hline 10 & $30^{\circ}$ & 18 & $30.1 \pm 0.7$ & $9.93 \pm 0.04$ & $0.33 \pm 0.007$ & $11.12 \pm 0.25$ \\
\hline & & & $40.5 \pm 0.9$ & $14.99 \pm 0.07$ & $0.37 \pm 0.009$ & $12.49 \pm 0.29$ \\
\hline & & & $49.5 \pm 1.7$ & $18.69 \pm 0.14$ & $0.378 \pm 0.013$ & $12.75 \pm 0.45$ \\
\hline & & & $10.3 \pm 0.5$ & $3.34 \pm 0.67$ & $0.324 \pm 0.067$ & $5.87 \pm 1.22$ \\
\hline & & & $19.2 \pm 0.6$ & $7.01 \pm 0.05$ & $0.364 \pm 0.011$ & $6.6 \pm 0.2$ \\
\hline 11 & $30^{\circ}$ & 36 & $29.3 \pm 0.6$ & $13.02 \pm 0.11$ & $0.444 \pm 0.01$ & $8.05 \pm 0.17$ \\
\hline & & & $40.2 \pm 0.8$ & $19.55 \pm 0.22$ & $0.487 \pm 0.011$ & $8.82 \pm 0.2$ \\
\hline & & & $50.8 \pm 0.8$ & $26.65 \pm 0.62$ & $0.525 \pm 0.015$ & $9.52 \pm 0.27$ \\
\hline
\end{tabular}




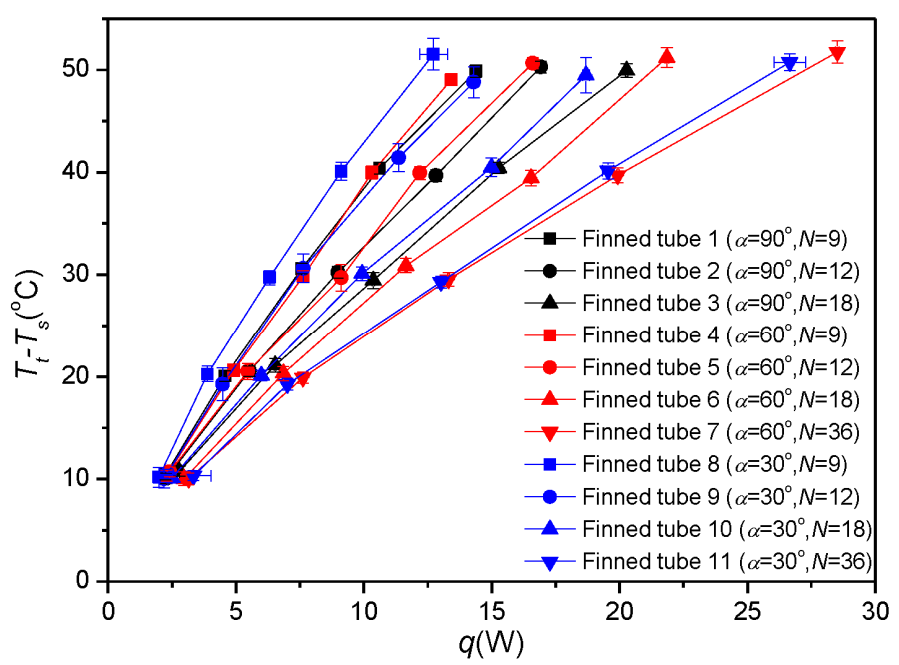

Figure 4. Temperature differences for several heat inputs, tilt angles, and numbers of fins.

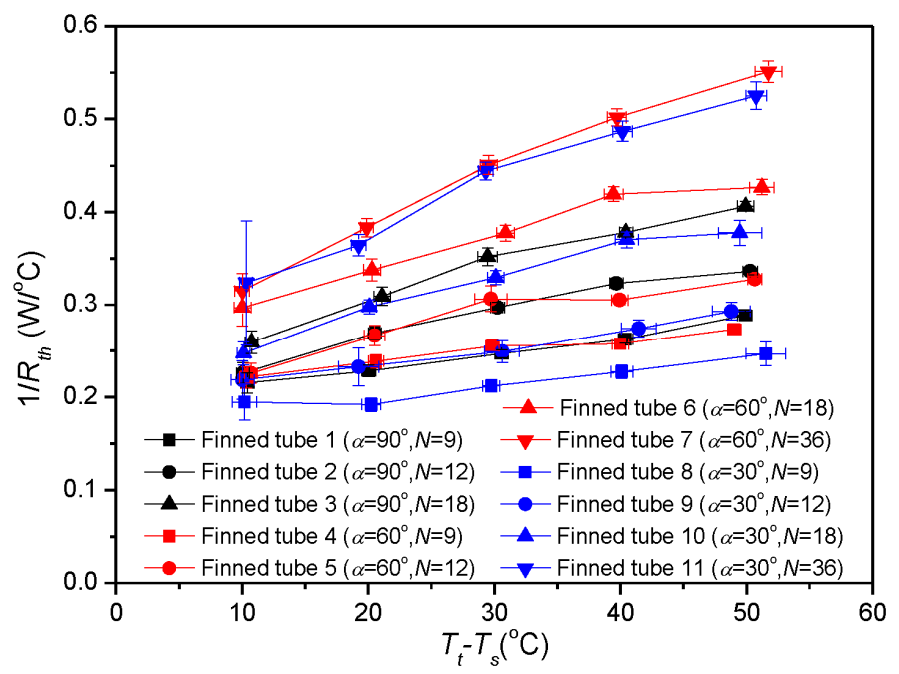

Figure 5. Cooling performances for several tilt angles and numbers of fins.

The Nusselt numbers $N u_{D}$ in Equation (5) are calculated from measured temperature differences and heat inputs by using Equations (1)-(9), and are tabulated in Table 2. In addition, the hydraulic diameter $D_{h}$ of the yellow region in Figure 2b, i.e., the channel between two adjacent fins, is given as:

$$
D_{h}=\frac{\pi(D+2 H)^{2} / N-\pi D^{2} / N-4 H_{f} t}{2 \pi R / N+2 H_{f}-t}
$$

Therefore, the dimensionless hydraulic diameter $D_{h}{ }^{*}$ can be defined as:

$$
D_{h}^{*}=\frac{D_{h}}{D}
$$

In the present study, the Nusselt number correlation for the horizontal tubes with tilted rectangular fins that best matches the measurement results is developed. The functional form of the Nusselt number correlation is proposed by modifying that for the horizontal tube without fins as follows:

$$
N u_{D}=f \cdot N u_{D, c y l}
$$


$N u_{D, c y l}$ is the Nusselt number for the horizontal tube without fins, and is given as the following equation [28]:

$$
N u_{D, c y l}=\left(0.60+\frac{0.387 R a_{D}^{1 / 6}}{\left(1+(0.559 / \operatorname{Pr})^{9 / 16}\right)^{8 / 27}}\right)^{2}
$$

In Equation (13), the Rayleigh number $R a_{D}$ is defined as Equation (14) in terms of the thermal diffusivity of the fluid $\alpha_{f}$, the kinematic viscosity of the fluid $v_{f}$, the volume expansion coefficient of the fluid $\beta_{f}$, and the gravitational acceleration $g$ :

$$
R a_{D}=\frac{g \beta_{f}\left(T_{w}-T_{a m b}\right) D^{3}}{v_{f} \alpha_{f}}
$$

The function $f$ in Equation (12) is related to the influence of the tilted fins on the heat dissipation. Function $f$ should monotonically decrease as the hydraulic diameter $D_{h}$ decreases. This decrease occurs because the heat dissipation from a fin is suppressed by adjacent fins owing to the overlap of the thermal boundary layers developing on the surfaces of the fins. As the hydraulic diameter $D_{h}$ decreases, the fin-by-fin spacing decreases, and the overlap of the thermal boundary layers and the suppression of the heat dissipation from the fins increases. Several functional forms for function $f$ that satisfy this condition are tested by using a least-squares fit on the measurement results, and it is found that the functional form:

$$
f=C_{1}-C_{2} \exp \left(-C_{3} D_{h}^{*}\right)
$$

best matches with the measurement results when the coefficients are given as:

$$
C_{1}=1.08, C_{2}=1.17, C_{3}=5.02
$$

The coefficient $C_{1}$ is the ratio of Nusselt numbers of the tubes with and without fins in the case when the hydraulic diameter of the space between two adjacent fins is much greater than the diameter of the tube. Therefore, the heat transfer coefficient of the tube with tilted fins is 1.08 times greater than that of the tube without tilted fins, when the hydraulic diameter is much greater than the tube diameter.

Finally, the Nusselt number correlation for the horizontal tubes with tilted rectangular fins under free convection is given as:

$$
N u_{D}=\left(1.08-1.17 \exp \left(-5.02 D_{h}^{*}\right)\right)\left(0.60+\frac{0.387 R a_{D}^{1 / 6}}{\left(1+(0.559 / \mathrm{Pr})^{9 / 16}\right)^{8 / 27}}\right)^{2}
$$

When the fin length is zero $\left(H=0, D_{h}{ }^{*}=0\right)$, the Nusselt number should be reduced to that for the horizontal tube without fins. To satisfy this limiting conduction, the correlation can be modified as follows:

$$
N u_{D}=\left(\left(2.17-2.18 \frac{H}{D}\right)-1.17 \exp \left(-5.02 D_{h}^{*}\right)\right)\left(0.60+\frac{0.387 R a_{D}^{1 / 6}}{\left(1+(0.559 / \mathrm{Pr})^{9 / 16}\right)^{8 / 27}}\right)^{2}
$$

Equations (17) and (18) are identical when $H / D$ is 0.5. In Figure 6a, the Nusselt numbers obtained from the measurement results for the tilt angles of $30^{\circ}$ and $60^{\circ}$ and those calculated from Equation (18) are presented as functions of the dimensionless hydraulic diameter. Figure 6a indicates that the Nusselt number is strongly dependent on the hydraulic diameter, and that the Nusselt number correlation is in good agreement with the measurement results within a $\pm 10 \%$ error. The Nusselt numbers obtained from the measurement results for the tubes with radial rectangular fins $(\alpha=0)$ presented in [24] are 
also compared with those calculated from Equation (18). The correlation can predict the Nusselt numbers of the tubes with radial rectangular fins within a $\pm 10 \%$ error, in spite of the fact that the correlation is developed for the tubes with tilted fins. In Figure $6 \mathrm{~b}$, the Nusselt numbers obtained from the measurement results for the tilt angle of $90^{\circ}$ are compared with those calculated from Equation (18). In this case, Equation (18) can predict the Nusselt number within a $\pm 20 \%$ error. In addition, another correlation for the Nusselt number is developed to improve the prediction regarding only the tilt angle of $90^{\circ}$, as in the following:

$$
N u_{D}=\left(0.932-1.03 \exp \left(-4.71 D_{h}^{*}\right)\right)\left(0.60+\frac{0.387 R a_{D}^{1 / 6}}{\left(1+(0.559 / \mathrm{Pr})^{9 / 16}\right)^{8 / 27}}\right)^{2}
$$

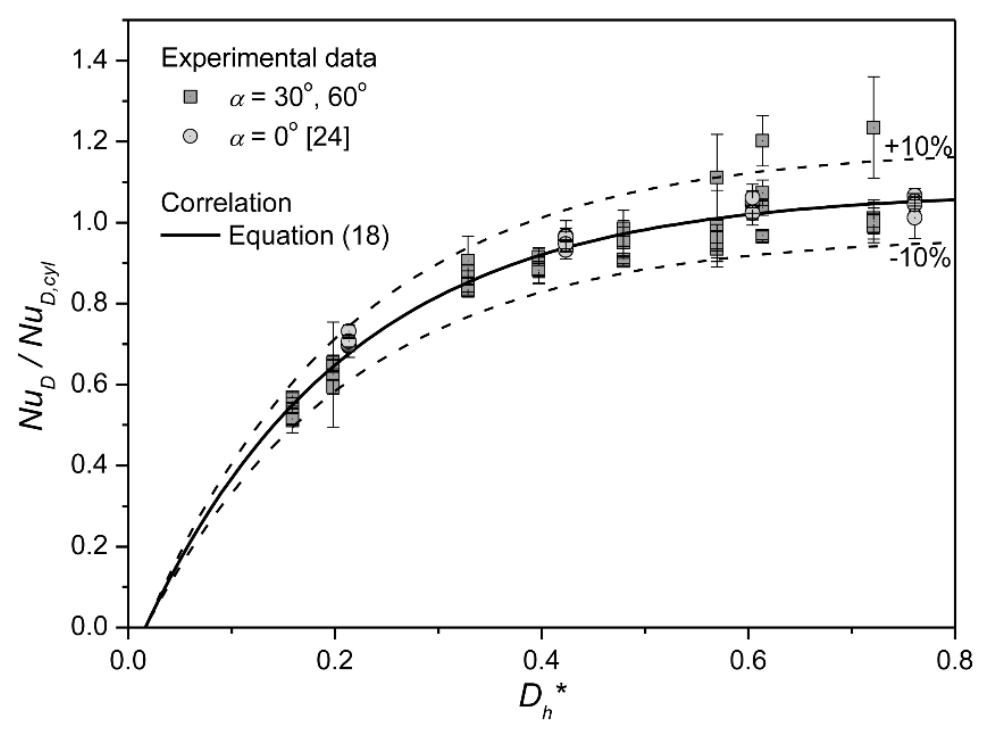

(a)

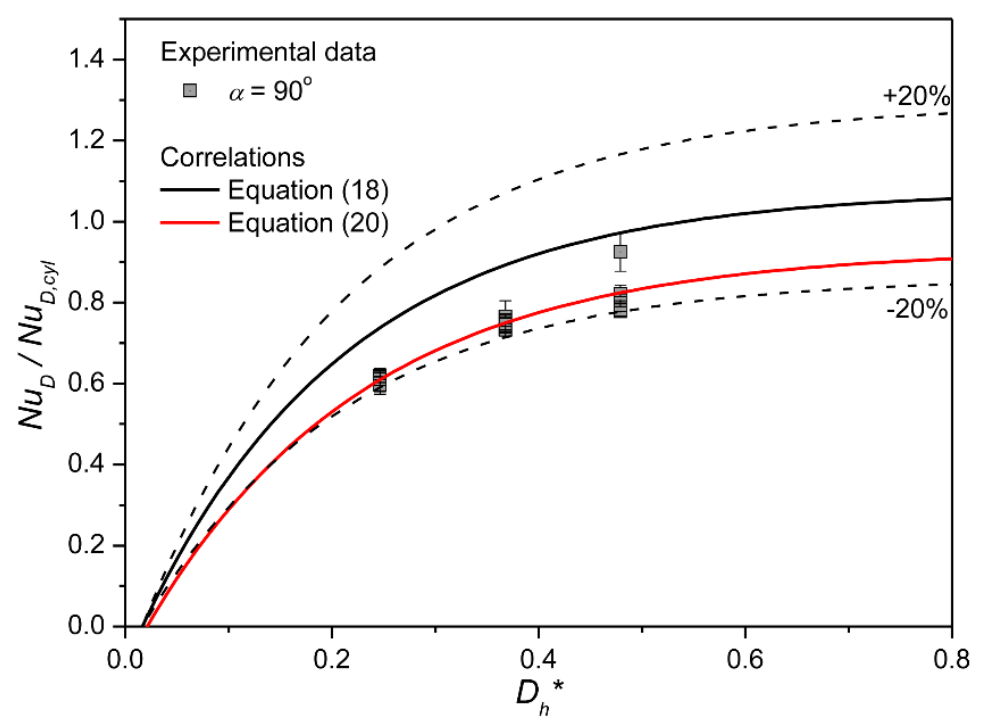

(b)

Figure 6. The Nusselt numbers obtained from measurement results and from the correlations. (a) Nusselt numbers for tilt angles of $0^{\circ}, 30^{\circ}$, and $60^{\circ} ;$ (b) Nusselt numbers for the tilt angle of $90^{\circ}$. 
When the fin length is zero $\left(H=0, D_{h}{ }^{*}=0\right)$, the Nusselt number should be reduced to that for the horizontal tube without fins. To satisfy this limiting conduction, Equation (19) can be modified as follows:

$$
N u_{D}=\left(\left(2.03-2.196 \frac{H}{D}\right)-1.03 \exp \left(-4.71 D_{h}^{*}\right)\right)\left(0.60+\frac{0.387 R a_{D}^{1 / 6}}{\left(1+(0.559 / \mathrm{Pr})^{9 / 16}\right)^{8 / 27}}\right)^{2}
$$

The functional forms of Equations (18) and (20) are identical; however, the values of the coefficients for function $f$ are slightly different. As shown in Figure 6b, Equation (20) can predict the Nusselt number within a $\pm 10 \%$ error.

As shown in Figure 6a,b, the ratio of the Nusselt number of the tube with tilted rectangular fins $\left(N u_{D}\right)$ to the Nusselt number of the tube without fins $\left(N u_{D, c y l}\right)$ is less than 1 . However, that does not mean that the tube without fins has better cooling performance compared to the tube with tilted rectangular fins. To compare the resistances of the tubes with and without tilted rectangular fins, it is useful to consider the ratio of the thermal resistance of the tube without fins $\left(R_{t h, c y l}\right)$ to the thermal resistance of the tube with tilted rectangular fins $\left(R_{t h}\right)$. This ratio satisfies the following equation:

$$
\frac{R_{t h, c y l}}{R_{t h}}=\frac{h A_{e f f}}{h_{c y l} A_{c y l}}=\frac{N u_{D}}{N u_{D, c y l}} \frac{A_{e f f}}{A_{c y l}}
$$

In this equation, $h_{c y l}$ is the heat transfer coefficient of the tube without fins and $A_{c y l}$ is the surface area of the tube without fins. This ratio of the thermal resistances is above 1 when the tube with tilted rectangular fins is better. On the other hand, this ratio is below 1 when the tube without fins is better. The effective surface area of the tube with tilted rectangular fins $\left(A_{\text {eff }}\right)$ is much greater compared to the surface area of the tube without fins $\left(A_{c y l}\right)$, because a lot of additional surface area is provided by the fins in the case of the tube with tilted rectangular fins. As a result, $A_{e f f} / A_{c y l}$ is much greater than 1 . Consequently, according to Equation (21), the ratio of the thermal resistances $R_{t h, c y l} / R_{t h}$ is greater than 1 , because $A_{\text {eff }} / A_{\text {cyl }}$ is much greater than 1 even though $N u_{D} / N u_{D, c y l}$ is less than 1 . The tube with tilted rectangular fins has much better cooling performance compared to the tube without fins in general.

Figures 7 and 8 show the cooling performances for several numbers of fins and tilt angles, respectively. In Figure 7, the cooling performance increases as the number of fins increases. This increase occurs mainly because the fin surface area increases as the number of fins increases. The cooling performance also increases as the temperature difference increases because free convection is driven by the buoyancy force, which increases as the temperature difference increases. In Figure 8 , the cooling performance increases as the tilt angle increases from $0^{\circ}$ to $60^{\circ}$, after which it decreases for $\alpha>60^{\circ}$. Therefore, there exists a specific tilt angle $\left(\alpha=60^{\circ}\right)$ for which the thermal resistance is maximized. The reason is that even though the effective surface area $\eta N A_{f}+A_{b}$ increases as the tilt angle increases, the heat transfer coefficient $h$ decreases because of the boundary layer overlap that resulted from the excessive decrease in fin spacing. In addition, the cooling performance of the tube without fins is also shown in Figures 7 and 8. As explained earlier, the cooling performance of the tube with tilted rectangular fins is much greater compared to that of the tube without fins.

Next, by using the proposed correlation, thermal optimization of horizontal tubes with tilted rectangular fins under free convection is conducted. The constraints and the properties used for thermal optimization are listed in Table 3. In Figure 9, a contour plot for the cooling performance is presented for various thicknesses and numbers of fins. In this figure, as the number of fins increases, the cooling performance rises. This occurs because the effective surface area rapidly increases as the number of fins increases, as shown in Figure 10. For the fixed number of fins, as the thickness of fins increases, the effective surface area increases due to an increase in the fin efficiency (Figure 10). 


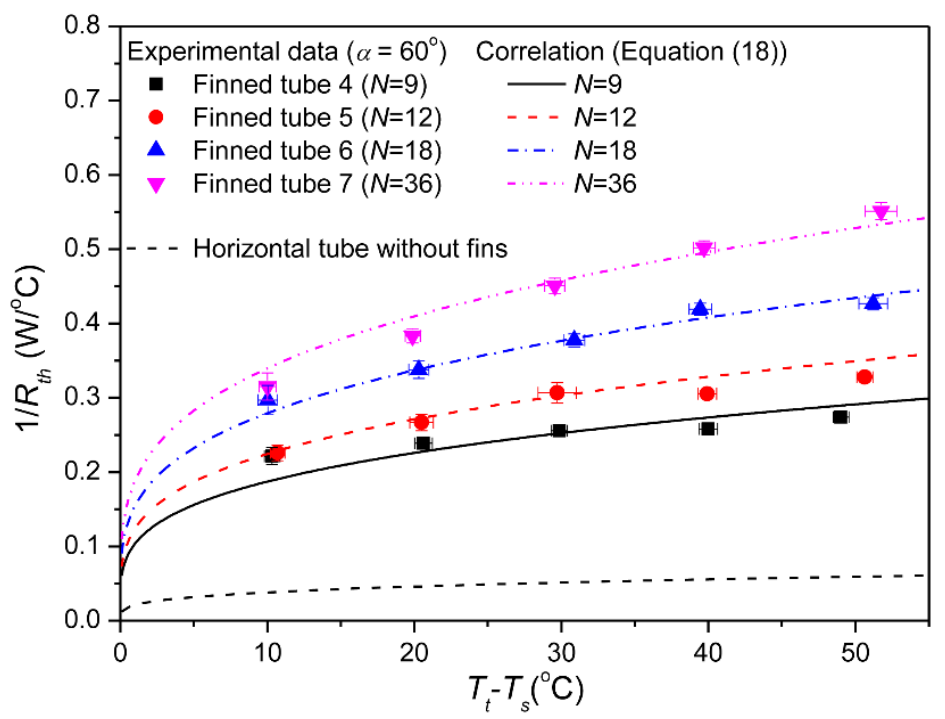

Figure 7. Cooling performances for several numbers of fins $\left(\alpha=60^{\circ}\right)$.

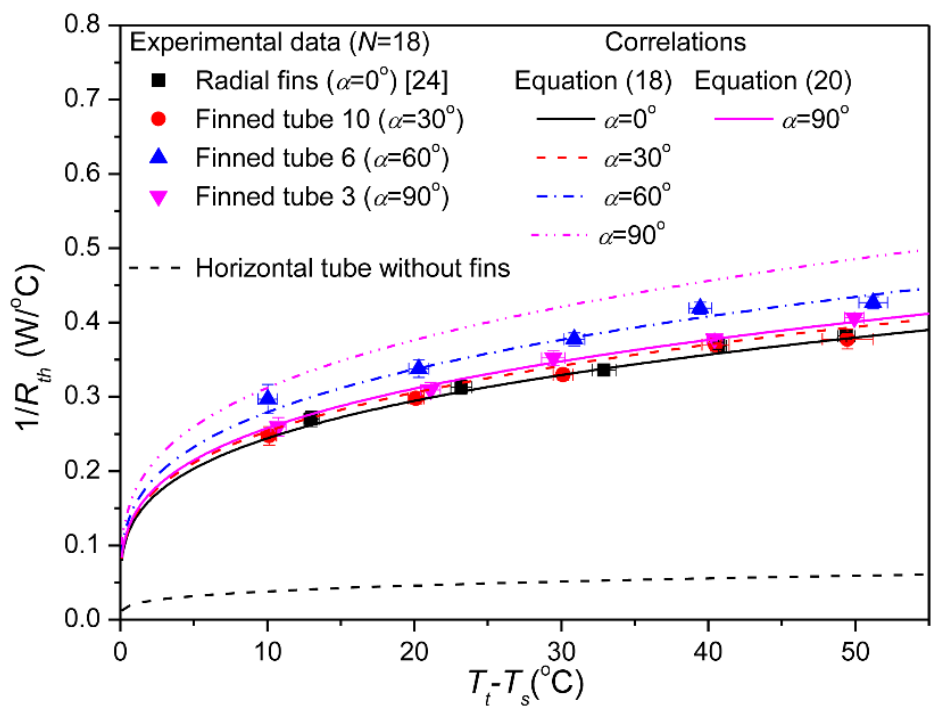

Figure 8. Cooling performances for several tilt angles $(N=18)$.

Table 3. Constraints and properties for thermal optimization.

\begin{tabular}{cccc}
\hline \multicolumn{2}{c}{ Constraints } & \multicolumn{2}{c}{ Properties } \\
\hline$T_{t}-T_{s}$ & $50^{\circ} \mathrm{C}$ & $\alpha_{f}$ & $2.23 \times 10^{-5} \mathrm{~m}^{2} / \mathrm{s}$ \\
$L$ & $50 \mathrm{~mm}$ & $\beta_{f}$ & $0.0033 / \mathrm{K}$ \\
$D$ & $60 \mathrm{~mm}$ & $v_{f}$ & $1.6 \times 10^{-5} \mathrm{~m}^{2} / \mathrm{s}$ \\
$H$ & $30 \mathrm{~mm}$ & $k_{f}$ & $0.026 \mathrm{~W} / \mathrm{m} \cdot \mathrm{K}$ \\
$N$ & $9-36$ & $k_{s}$ & $220 \mathrm{~W} / \mathrm{m} \cdot \mathrm{K}$ \\
$\alpha$ & $60^{\circ}$ & - & - \\
\hline
\end{tabular}




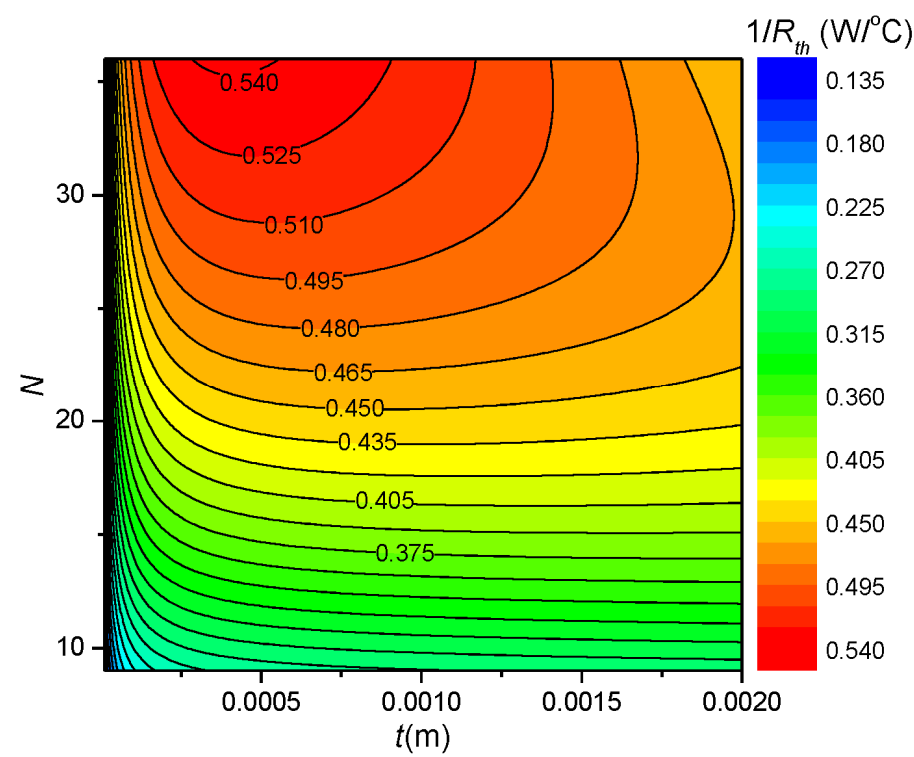

Figure 9. Contour plot of cooling performance.

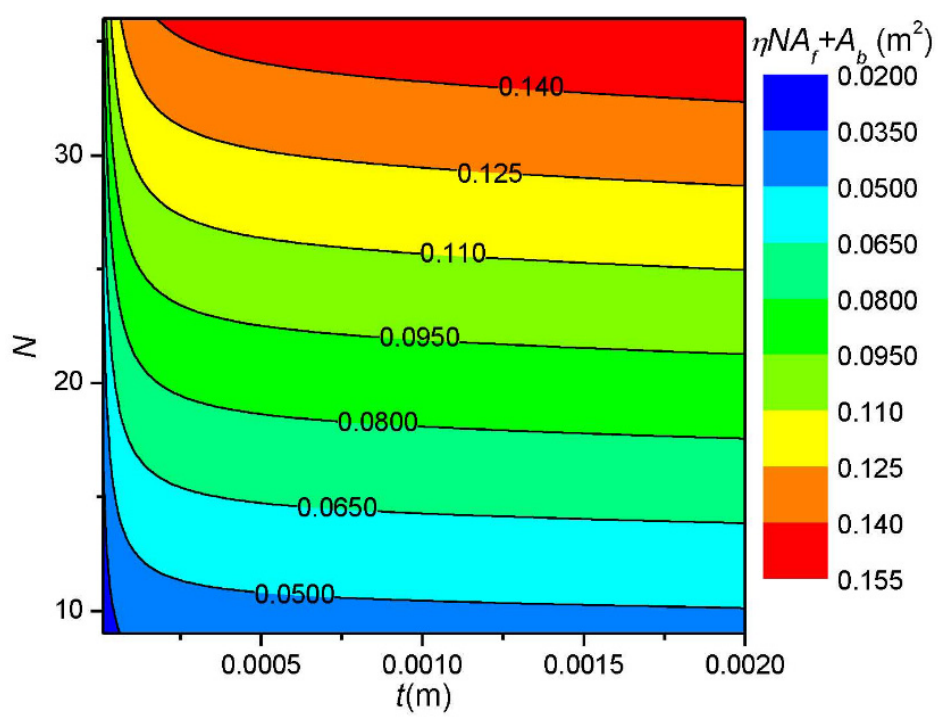

Figure 10. Contour plot of the effective surface area.

However, as the thickness of fins increases, the heat transfer coefficient decreases due to a decrease in fin-by-fin spacing (Figure 11). As a result, for the fixed number of fins, there exists a specific thickness of fins for which the cooling performance is maximized in Figure 9. Finally, Figure 9 shows that the optimal cooling performance of the tube with tilted rectangular fins is $0.543 \mathrm{~W} / \mathrm{K}$. For comparison, the cooling performances of the tubes with conventional radial rectangular fins are presented for various thicknesses and numbers of fins in Figure 12. The optimal cooling performance of the tube with conventional radial rectangular fins is $0.513 \mathrm{~W} / \mathrm{K}$. Finally, Figure 13 shows the comparison of the optimal cooling performances of tubes with tilted rectangular fins and conventional radial rectangular fins. As shown in the figure, the optimal cooling performance of the tilted finned tube with a tilt angle of $60^{\circ}$ is $6 \%$ greater than that of the radial finned tube. Therefore, the tube with tilted rectangular fins can have better cooling performance compared to the tube with radial rectangular fins, if properly designed. In addition, the cooling performance of the tube without fins is also shown in Figure 13. The optimal cooling performance of the tilted finned tube with a tilt angle of $60^{\circ}$ is 9.2 times greater than that of the tube without fins. 


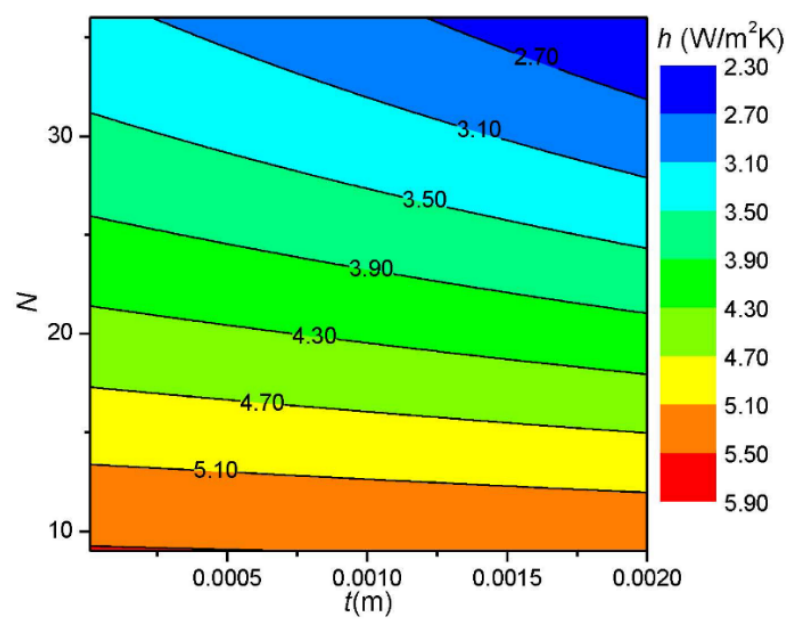

Figure 11. Contour plot of the heat transfer coefficient.

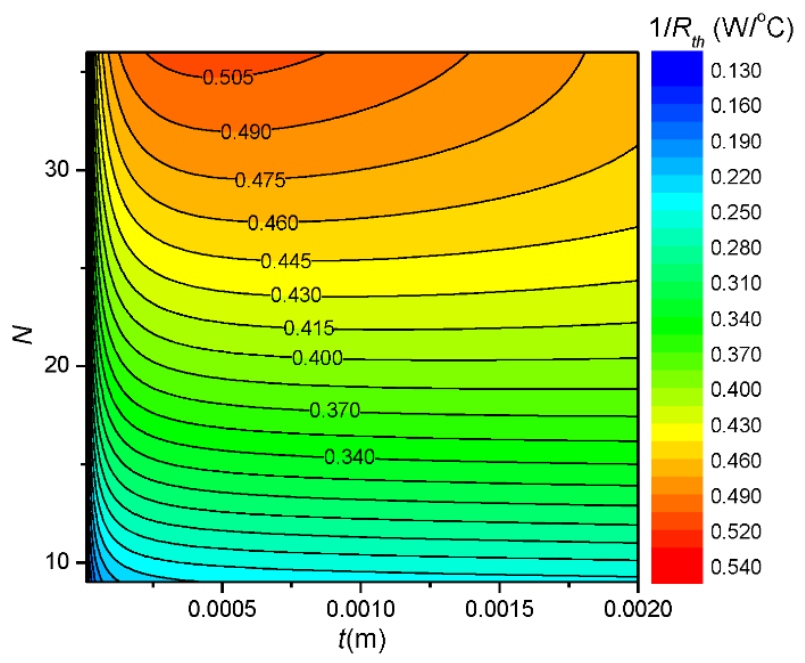

Figure 12. Contour plot of cooling performance of the tube with conventional radial rectangular fins.

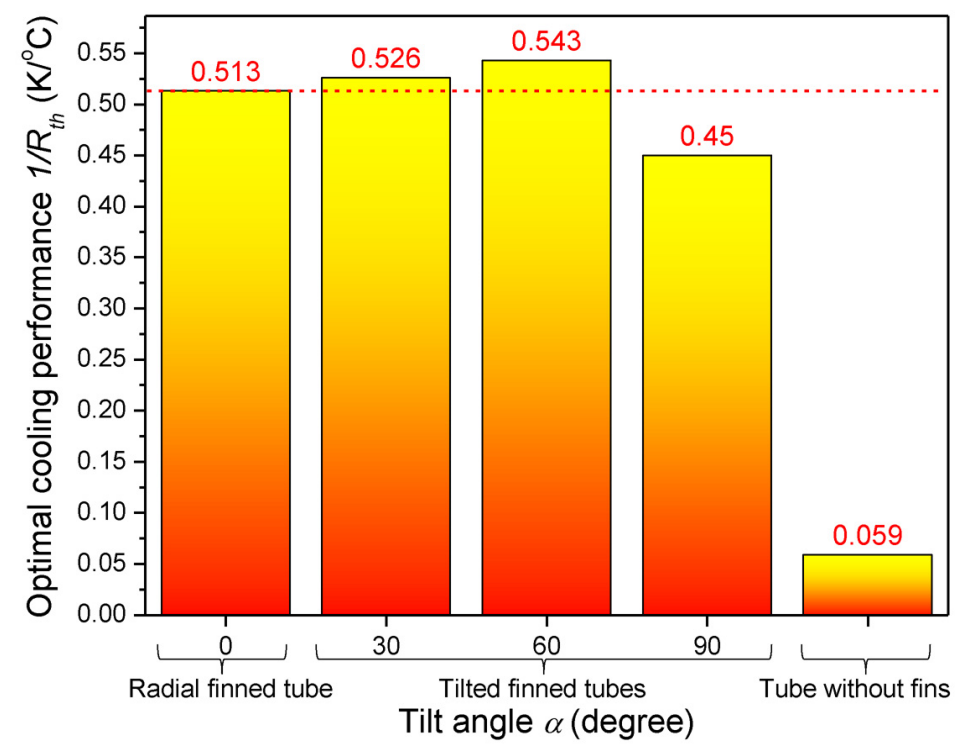

Figure 13. Comparison of the optimal cooling performances. 
Last of all, the optimal dimensions and optimal cooling performances of the tube with tilted fins in the horizontal and vertical configuration are listed in Table 4 . The table shows that the optimal cooling performance varies significantly, depending on the orientation. Therefore, orientation dependence should be considered carefully if the orientation of the tube with tilted fins is not always fixed, and may need to be adjusted for the cooling of electronic devices, such as retrofit LED bulbs [5].

Table 4. Optimal dimensions and optimal cooling performances of tubes with tilted fins.

\begin{tabular}{|c|c|c|c|}
\hline Configuration & $N$ & $t[\mathrm{~mm}]$ & $1 / R_{t h}[\mathrm{~W} / \mathrm{K}]$ \\
\hline Horizontal & 36 & 0.4 & 0.543 \\
\hline Vertical [27] & 36 & 0.62 & 0.943 \\
\hline
\end{tabular}

\section{Conclusions}

In the present study, the horizontal tubes with tilted rectangular fins under free convection have been experimentally investigated. The temperature differences of horizontal tubes with tilted rectangular fins were measured for several heat inputs, tilt angles, and numbers of fins. Using the measurement results, a correlation for the prediction of the Nusselt number was suggested. The correlation is suitable for the ranges of Rayleigh numbers of 200,000-1,100,000, tilt angles of $0-90^{\circ}$, and numbers of fins of 9-36, in which the experimental data were obtained. On the basis of the suggested correlation, the cooling performances were presented for various numbers of fins and thicknesses of fins, and the value of the optimal cooling performance was found. Then, the optimal cooling performances of tubes with tilted rectangular fins and conventional radial rectangular fins were compared. Finally, the comparison results showed that the optimal cooling performance of the tilted finned tube with a tilt angle of $60^{\circ}$ is $6 \%$ greater than that of the tube with radial rectangular fins. In addition, the optimal cooling performance of the tilted finned tube is 9.2 times greater than that of the tube without fins. Therefore, tilted rectangular fins may potentially be used for the cooling of various electronic devices.

\section{Appendix A. Uncertainty Analysis}

The uncertainty in the measurement was obtained from the following equation:

$$
U=\left(B^{2}+P^{2}\right)^{1 / 2}=\left(B^{2}+\frac{t_{95 \%}^{2} s^{2}}{N_{\text {data }}}\right)^{1 / 2}
$$

In this equation, $U, B, P, N_{\text {data }}, s$, and $t_{95 \%}$ are the uncertainty, bias error, precision error, number of data, standard deviation of data, and t-distribution for a confidence level of $95 \%$, respectively.

Acknowledgments: This research was supported by Nano-Material Technology Development Program through the National Research Foundation of Korea (NRF) funded by the Ministry of Science, ICT and Future Planning (NRF-2011-0030285). This work was supported by "Human Resources Program in Energy Technology" of the Korea Institute of Energy Technology Evaluation and Planning (KETEP), granted financial resource from the Ministry of Trade, Industry \& Energy, Republic of Korea. (Project No: 20154010 200820).

Author Contributions: Jong Bum Lee and Dong-Kwon Kim conceived and designed the experiments; Jong Bum Lee performed the experiments; Hyun Jung Kim and Dong-Kwon Kim analyzed the data; Dong-Kwon Kim wrote the paper.

Conflicts of Interest: The authors declare no conflict of interest.

\section{References}

1. Cengel, Y.A. Heat Transfer, 2nd ed.; McGraw-Hill: New York, NY, USA, 2003.

2. Oktay, S.; Hannemann, R.J.; Bar-Cohen, A. High Heat from a Small Package. Mech. Eng. 1986, 108, 36-42. 
3. Bar-Cohen, A. Thermal Management of Electric Components with Dielectric Liquids. JSME Int. J. Ser. B Fluids Therm. Eng. 1993, 36, 1-25. [CrossRef]

4. E Pop, Energy Dissipation and Transport in Nanoscale Devices. Nano Res. 2010, 3, 147-169.

5. Lasance, C.J.M.; Poppe, A. (Eds.) Thermal Management for LED Applications; Springer: New York, NY, USA, 2014.

6. Chang, M.-H.; Das, D.; Varde, P.V.; Pecht, M. Light Emitting Diodes Reliability Review. Microelectron. Reliab. 2012, 52, 762-782. [CrossRef]

7. Liu, J.; Tam, W.S.; Wong, H.; Filip, V. Temperature-dependent Light-Emitting Characteristics of InGaN/GaN Diodes. Microelectron. Reliab. 2009, 49, 38-41. [CrossRef]

8. Park, J.; Shin, M.; Lee, C.C. Measurement of temperature profiles on visible light-emitting diodes by use of a nematic liquid crystal and an infrared laser. Opt. Lett. 2004, 29, 2656-2658. [CrossRef] [PubMed]

9. Luo, X.; Liu, S. A Microjet Array Cooling System for Thermal Management of High-brightness LEDs. IEEE Trans. Adv. Packag. 2007, 30, 475-484. [CrossRef]

10. Narendran, N.; Gu, Y. Life of LED-based White Light Sources. J. Disp. Technol. 2005, 1, 167-171. [CrossRef]

11. Incropera, F.P. Convection Heat Transfer in Electronic Equipment Cooling. J. Heat Transf. 1988, 110, $1097-1111$. [CrossRef]

12. Nakayama, W. Thermal Management of Electronic Equipment: A Review of Technology and Research Topics. Appl. Mech. Rev. 1986, 39, 1847-1868. [CrossRef]

13. Welling, J.R.; Wooldridge, C.B. Free Convection Heat Transfer Coefficients from Rectangular Vertical Fins. J. Heat Transf. 1965, 87, 439-444. [CrossRef]

14. Martynenko, O.G.; Khramtsov, P.P. Free-Convective Heat Transfer; Springer: New York, NY, USA, 2005.

15. Raithby, G.D.; Hollands, K.G.T. Natural convection. In Handbook of Heat Transfer, 3rd ed.; Rohsenow, W.M., Hartnett, J.P., Cho, Y.I., Eds.; McGraw-Hill: New York, NY, USA, 1998.

16. Shah, R.K.; Sekulić, D.P. Fundamentals of Heat Exchanger Design; John Wiley \& Sons: Hoboken, NJ, USA, 2003.

17. Sparrow, E.M.; Bahrami, P.A. Experiments on Natural Convection Heat Transfer on the Fins of a Finned Horizontal Tube. Int. J. Heat Mass Transf. 1980, 23, 1555-1560. [CrossRef]

18. Chen, H.-T.; Chou, J.-C. Investigation of Natural-Convection Heat Transfer Coefficient on a Vertical Square Fin of Finned-Tube Heat Exchangers. Int. J. Heat Mass Transf. 2006, 49, 3034-3044. [CrossRef]

19. Yildiz, Ş.; Yüncü, H. An Experimental Investigation on Performance of Annular Fins on a Horizontal Cylinder in Free Convection Heat Transfer. Heat Mass Transf. 2004, 40, 239-251. [CrossRef]

20. Hahne, E.; Zhu, D. Natural Convection Heat Transfer on Finned Tubes in Air. Int. J. Heat Mass Transf. 1994, 37, 59-63. [CrossRef]

21. Yu, S.-H.; Lee, K.-S.; Yook, S.-J. Natural Convection around a Radial Heat Sink. Int. J. Heat Mass Transf. 2010, 53, 2935-2938. [CrossRef]

22. Yu, S.-H.; Lee, K.-S.; Yook, S.-J. Optimum Design of a Radial Heat Sink under Natural Convection. Int. J. Heat Mass Transf. 2011, 54, 2499-2505. [CrossRef]

23. An, B.H.; Kim, H.J.; Kim, D.-K. Nusselt Number Correlation for Natural Convection from Vertical Cylinders with Vertically Oriented Plate Fins. Exp. Therm. Fluid Sci. 2012, 41, 59-66. [CrossRef]

24. Kim, H.J.; An, B.H.; Park, J.; Kim, D.-K. Experimental Study on Natural Convection Heat Transfer from Horizontal Cylinders with Longitudinal Plate Fins. J. Mech. Sci. Technol. 2013, 27, 593-599. [CrossRef]

25. Takeishi, K.; Oda, Y.; Miyake, Y.; Motoda, Y. Convective Heat Transfer and Pressure Loss in Rectangular Ducts with Inclined Pin-Fin on a Wavy Endwall. J. Eng. Gas Turbines Power 2013, 135, 061902. [CrossRef]

26. Hagote, R.B.; Dahake, S.K. Study of Natural Convection Heat Transfer on Horizontal, Inclined and Vertical Heated Plate by V-Fin Array. Int. J. Sci. Eng. Res. 2014, 5, 1366-1374.

27. Lee, J.B.; Kim, H.J.; Kim, D.-K. Experimental Study of Natural Convection Cooling of Vertical Cylinders with Inclined Plate Fins. Energies 2016, 9, 391. [CrossRef]

28. Churchill, S.W.; Chu, H.H.S. Correlating equations for laminar and turbulent free convection from a horizontal cylinder. Int. J. Heat Mass Transf. 1975, 18, 1049-1053. [CrossRef]

(C) 2017 by the authors. Licensee MDPI, Basel, Switzerland. This article is an open access article distributed under the terms and conditions of the Creative Commons Attribution (CC BY) license (http://creativecommons.org/licenses/by/4.0/). 